\title{
HSCT FOR AUTOIMMUNE DISEASES
}

\author{
Maria Carolina Oliveira ${ }^{1,2}$, Milton Artur Ruiz, ${ }^{3}$, Daniela Moraes ${ }^{1}$, Juliana Elias Dias ${ }^{1}$, Lilian Piron-Ruiz ${ }^{3}$, \\ Andreza Feitosa Ribeiro ${ }^{4}$, Morgani Rodrigues ${ }^{4}$, Nelson Hamerschlak ${ }^{4}$

\begin{abstract}
1Department of Internal Medicine, Ribeirão Preto Medical School, University of São Paulo, Ribeirão Preto, Brazil 2Center for Cell-based Therapy, Regional Blood Center, Ribeirão Preto Medical School, University of São Paulo, Ribeirão Preto, Brazil - 3 Bone Marrow Transplantation and Cell Therapy Unit, Associação Portuguesa de Beneficência de São José do Rio Preto, São José do Rio Preto, Brazil - 4Bone Marrow Transplantation Unit, Hospital Israelita Albert Einstein, São Paulo, Brazil Key words: autoimmune diseases, hematopoietic stem cell transplantation, multiple sclerosis, systemic sclerosis, Crohn's disease
\end{abstract}

Correspondence to: mcarolor@usp.br

Autologous hematopoietic stem cell transplantation (AHSCT) has been used worldwide as treatment for autoimmune disease patients, and although different centers have slightly different approaches, the main strategy remains similar ${ }^{1}$. Briefly, the procedure consists of a first phase, when autologous hematopoietic stem cells are harvested (mobilized) and cryopreserved, and a second phase, including conditioning regimen and infusion of stem cells. The aim of AHSCT is to promote immune depletion, eliminate autoreactive lymphocytes and reprogram the immune system, restoring long-lasting immune tolerance. As result, patients maintain long-term clinical remission in absence of further immunosuppression.

Three of the most important and current indications for AHSCT are multiple sclerosis (MS), systemic sclerosis (ES) and Crohn's disease (CD) ${ }^{[1]}$. The American Society for Cellular Transplantation and Therapy (ASTCT), the European Society for Blood and Marrow Transplantation (EBMT) and the Brazilian Society of Bone Marrow Transplantation (SBTMO) currently consider AHSCT as part of the already established therapeutic strategies for these three autoimmune disorders, apart from the research setting.

\section{MULTIPLE SCLEROSIS}

In addition to numerous studies published since 1993, two randomized clinical trials are available in the literature. In the ASTIMS study, AHSCT was compared to mitoxantrone; 9 of 21 MS patients were randomized to $\mathrm{AHSCT}$, conditioned with BEAM and rabbit antithymocyte globulin (ATG) ${ }^{2}$. In this study, patients with an average disease duration of 10 years were included, most of them already in the secondarily progressive phase of the disease. Over 4 years, the average number of new T2-weighted magnetic resonance imaging (MRI) lesions was 2.5 in the AHSCT group versus 8 in the mitoxantrone group $(p=0.00016)$. None of the transplanted patients presented new MS lesions at MRI with gadolinium. The progression of the Expanded Disability Status Score (EDSS) was similar in both groups, worsening in $57 \%$ of the patients in the AHSCT group, versus $48 \%$ in the mitoxantrone group $(p=0.50)$. More recently, a multicenter study compared AHSCT with the best available treatment chosen by the neurologists at each center ${ }^{3}$. One hundred and ten patients with highly inflammatory MS (relapsing-remitting subset and inflammation on MRI) were randomized. The AHSCT group was conditioned with $200 \mathrm{mg} / \mathrm{kg}$ cyclophosphamide plus rabbit ATG. In the first year of follow-up, the EDSS decreased (neurological improvement) in the transplanted patients, while increased in the non-transplanted patients $(p<0.01)$. In 5-year follow-up, the EDSS worsened in $3 / 52$ (5.8\%) patients in the AHSCT group, against 34/51 (66.7\%) in the non-transplanted group, and there were relapses in $15.4 \%$ of patients in the AHSCT group versus $85.2 \%$ in the non-transplanted group. There were no deaths or grade 4 toxicities related to transplant.

In 2019, the American Society for Transplantation and Cell Therapy (ASTCT) published a comprehensive review of the literature and recommended $\mathrm{AH}$ - 
SCT as "standard of care, available clinical evidence" for relapsing-remitting, treatment-refractory $\mathrm{MS}^{[4]}$.

Patients to be considered for transplantation should have inflammatory phenotypes of MS, which include patients with the relapsing-remitting form having presented well-defined relapses in the last 12 months, or patients with the secondary progressive form showing inflammatory lesions (gadolinium enhancement or new T2 lesions) on MRI images in the last 12 months.

\section{SYSTEMIC SCLEROSIS}

Case reports and phase I/II studies have been published since 1996, demonstrating safety and efficacy of autologous transplantation for SSc. In the last decade, three randomized studies have shown that AHSCT is superior to conventional treatment in patients with SSc, promoting greater overall survival, progression-free survival and quality of life.

The first study included 19 SSc patients, who were randomized either to non-myeloablative AHSCT with 200 $\mathrm{mg} / \mathrm{kg}$ cyclophosphamide plus rabbit ATG or to conventional treatment with cyclophosphamide monthly pulses ${ }^{[5]}$. In a two-year follow-up, AHSCT was more effective in controlling skin involvement, lung function and improving quality of life than conventional treatment. No deaths were reported. The second study, led by the EBMT, compared 79 transplanted SSC patients with 77 others, treated with cyclophosphamide monthly pulses, showing superiority of AHSCT in terms of overall survival, progression-free survival and quality of life ${ }^{[6]}$. Although the final outcomes were positive, this study showed a transplant-related mortality of approximately $10 \%$, mainly due to cardiac causes $^{[7]}$. As result of this and other studies, the EBMT and partners now recommend careful cardiac evaluation before enrolling a patient for AHSCT, aiming to improve patient selection and reduce treatment-related mortality ${ }^{[8,9]}$. Cardiac evaluation should include electrocardiogram, echocardiogram, 24h-Holter, cardiac resonance and right-side cardiac catheterization with volume overload8.

The third study, multicenter randomized, compared 36 SSc patients undergoing myeloablative AHSCT, with 39 treated with cyclophosphamide pulses ${ }^{[10]}$. The transplant-conditioning regimen included lowdose cyclophosphamide plus total body irradiation and horse ATG. The study demonstrated greater overall survival and progression-free survival in transplanted patients compared to the non-transplanted group. A transplant-related mortality of 3\% was observed.
Since 2017, the European League Against Rheumatism (EULAR) has recommended AHSCT for patients with rapidly progressive $\mathrm{SSC}$ at risk of organ failure ${ }^{[1]}$. Since 2018, the ASTCT has also recommended autologous transplantation as standard treatment for severe cases of $\mathrm{SSc}^{[12]}$. Treatment protocols have been refined and incorporated into the routine of several transplant centers.

AHSCT is indicated for patients with diffuse SSc with worsening of skin involvement, or patients with interstitial lung disease with worsening of lung function, in the last 6 months, refractory to immunosuppressive treatment.

\section{CROHN'S DISEASE}

AHSCT has emerged as a potential treatment for CD due to the chronicity of the disease and lack of therapeutic options in refractory patients. Since 1993, there have been reports of patients with $C D$ who had concomitant leukemias or lymphomas, with complete remission of both diseases after hematopoietic stem cell transplantation. In 2010, researchers from the Northwestern University (Chicago, USA) described the long-term follow-up of 24 patients with severe, active and refractory $\mathrm{CD}$ who underwent $\mathrm{AH}$ SCT with $200 \mathrm{mg} / \mathrm{kg}$ cyclophosphamide and rabbit ATG ${ }^{[13]}$. The study showed an excellent remission rate after AHSCT, but with high incidence of disease reactivation in the long-term follow-up. The progression-free survival of CD patients was $91 \%$ in the first year, $63 \%$ in the second, $57 \%$ in the third, $39 \%$ in the fourth and $19 \%$ in the fifth year after AHSCT. Nevertheless, when compared to conventional treatment, AHSCT outcomes are quite encouraging. The Crohn's Disease Activity Index (CDAl), used in the routine assessment of $C D$ patients, must be less than 150 to indicate remission ${ }^{[14]}$. Conventional medications (synthetic and biological immunosuppressants) induce clinical remission in 40 to $50 \%$ of patients in one year, and this percentage also decreases over time. Thus, when studies show that AHSCT induces clinical remission (CDAl $<150)$ in more than $80 \%$ of patients in the first year, these results can be interpreted as favoring AHSCT.

In 2017, the EBMT published a study that included 45 patients with active $C D$ and who were refractory to conventional treatment ${ }^{[15]}$. Patients were randomized to either only mobilization with $4 \mathrm{~g} / \mathrm{m} 2$ of cyclophosphamide or to mobilization followed by AHSCT with $200 \mathrm{mg} / \mathrm{kg}$ of cyclophosphamide plus rabbit ATG. The primary endpoint of this study, however, was excessively stringent, as complete clinical, radiological and endoscopic remission (a sustained dis- 
ease remission composite score) should be achieved at the end of the first year. As consequence, there were no differences in the number of patients who met the sustained disease remission target, between transplanted and non-transplanted patients. For secondary endpoints of disease activity, endoscopic activity and use of medical therapy, results favored the group of transplanted patients.

A subsequent reassessment of the results from the same study, using more traditional evaluating tools, led to conclusions that AHSCT promotes clinical and endoscopic benefits, despite the high number of adverse events ${ }^{[16]}$. Other transplant centers, including from Brazil, have shown beneficial results from non-myeloablative AHSCT ${ }^{[17]}$. The studies demonstrate acceptable toxicity of the procedure with reduced doses $(2 \mathrm{~g} / \mathrm{m} 2)$ of cyclophosphamide in the mobilization phase, and improvement of the immediate and long-term quality of life in patients undergoing AHSCT. The mortality rate was zero in most studies. In a large number of cases, there were endoscopic remissions with healing of lesions and remissions in imaging studies.
Allogeneic HSCT may be a future option. A recent pilot study with 9 patients undergoing allogeneic transplantation showed that the procedure was effective in controlling the disease in the short and long term ${ }^{[18]}$. However, there was high transplant-related toxicity and one patient died due to infection by adenovirus three months after transplantation.

To date, the EBMT, the Center for International Blood and Marrow Transplant Research (CIBMTR), and communications from the United States and Brazil report a total of 334 transplants for CD, 318 of which are autologous, characterizing this autoimmune disease as the third most frequently transplanted in the world. These data reflect the severity of the disease and the demand for more effective therapeutic resources. Patients with clinically and endoscopically active CD, refractory to conventional treatment including at least two biological drugs, should be indicated for autologous transplantation.

In conclusion, data from national and international studies provide scientific support to recommend AHSCT as treatment for multiple sclerosis, systemic sclerosis and Crohn's disease (Table 1). Allogeneic transplantation, however, should still be further evaluated in the experimental setting.

\section{REFERENCES:}

1.Snowden JA, Sharrack B, Akil M, Kiely DG, Lobo A, Kazmi M, et al. Autologous haematopoietic stem cell transplantation (aHSCT) for severe resistant autoimmune and inflammatory diseases - a guide for the generalist. Clin Med (Lond); v. 18, n.4, p.329-34, 2018.

2.Mancardi GL, Sormani MP, Gualandi F, Saiz A, Carreras $E$, Merelli $E$, et al. Autologous hematopoietic stem cell transplantation in multiple sclerosis: a phase II trial. Neurology;v. 84, n. 10, p.981-8, 2015.

3.Burt RK, Balabanov R, Burman J, Sharrack B, Snowden JA, Oliveira MC, et al. Effect of Nonmyeloablative Hematopoietic Stem Cell Transplantation vs Continued Disease-Modifying Therapy on Disease Progression in Patients With Relapsing-Remitting Multiple Sclerosis: A Randomized Clinical Trial. JAMA; v. 321. n. 2. p.165-74, 2019.

4.Cohen JA, Baldassari LE, Atkins HL, Bowen JD, Bredeson C, Carpenter P, et al. Autologous Hematopoietic Cell Transplantation for Treatment-Refractory Relapsing Multiple Sclerosis: Position Statement from the American Society for Blood and Marrow Transplantation. Biol Blood Marrow Transplant; v. 25, n. 5, p.845-54, 2019.
5.Burt RK, Shah SJ, Dill K, Grant T, Gheorghiade M, Schroeder J, et al. Autologous non-myeloablative haemopoietic stem-cell transplantation compared with pulse cyclophosphamide once per month for systemic sclerosis (ASSIST): an open-label, randomised phase 2 trial. Lancet; $v$. 378, n, 9790, p.498-506, 2011

6.van Laar JM, Farge D, Sont JK, Naraghi K, Marjanovic Z, Larghero J, et al. Autologous hematopoietic stem cell transplantation vs intravenous pulse cyclophosphamide in diffuse cutaneous systemic sclerosis: a randomized clinical trial. JAMA; v. 311, n. 24, p.2490-8, 2014.

7.Burt RK, Oliveira MC, Shah SJ. Cardiac assessment before stem cell transplantation for systemic sclerosis. JAMA; v. 312, n. 17, p.1803, 2014.

8.Farge D, Burt RK, Oliveira MC, Mousseaux E, Rovira M, Marjanovic Z, et al. Cardiopulmonary assessment of patients with systemic sclerosis for hematopoietic stem cell transplantation: recommendations from the European Society for Blood and Marrow Transplantation Autoimmune Diseases Working Party and collaborating partners. Bone Marrow Transplant. v.52, n.11, p. 1495-1503. 
9.Burt RK, Oliveira MC, Shah SJ, Moraes DA, Simoes $B$, Gheorghiade $M$, et al. Cardiac involvement and treatment-related mortality after non-myeloablative haemopoietic stem-cell transplantation with unselected autologous peripheral blood for patients with systemic sclerosis: a retrospective analysis. Lancet; v. 381, n. 9872, p.1116-24, 2013.

10.Sullivan KM, Goldmuntz EA, Keyes-Elstein L, McSweeney PA, Pinckney A, Welch B, et al. Myeloablative Autologous Stem-Cell Transplantation for Severe Scleroderma. N Engl J Med; v. 378, n. 1, p.35-47, 2018.

11.Kowal-Bielecka O, Fransen J, Avouac J, Becker M, Kulak A, Allanore Y, et al. Update of EULAR recommendations for the treatment of systemic sclerosis. Ann Rheum Dis; v. 76, n.8, p.1327-39, 2017.

12.Sullivan KM, Majhail NS, Bredeson C, Carpenter PA, Chatterjee S, Crofford LJ, et al. Systemic Sclerosis as an Indication for Autologous Hematopoietic Cell Transplantation: Position Statement from the American Society for Blood and Marrow Transplantation. Biol Blood Marrow Transplant; v. 24, n. 10, p.1961-4, 2018.

13.Burt RK, Craig RM, Milanetti F, Quigley K, Gozdziak $\mathrm{P}, \mathrm{Bucha} \mathrm{J}$, et al. Autologous nonmyeloablative hematopoietic stem cell transplantation in patients with severe anti-TNF refractory Crohn disease: long-term follow-up. Blood; v. 116, n.26, p.6123-32, 2010.

14.Torres J, Mehandru S, Colombel JF, Peyrin-Biroulet L. Crohn's disease. Lancet. 2017;389(10080):1741-55.

15. Hawkey CJ, Allez M, Clark MM, Labopin M, Lindsay JO, Ricart E, et al. Autologous Hematopoetic Stem Cell Transplantation for Refractory Crohn Disease: A Randomized Clinical Trial. JAMA; v. 389, n.10080, p. 1741-1755, 2017.

16.Lindsay JO, Allez M, Clark M, Labopin M, Ricart E, Rogler G, et al. Autologous stem-cell transplantation in treatment-refractory Crohn's disease: an analysis of pooled data from the ASTIC trial. Lancet Gastroenterol Hepatol; v.2, n.6, p.2524-34, 2017.

17.Ruiz MA, Kaiser RL Jr, de Quadros LG, Piron-Ruiz L, Peña-Arciniegas T, Faria MAG, et al. Low toxicity and favorable clinical and quality of life impact after non-myeloablative autologous hematopoietic stem cell transplant in Crohn's disease. BMC Res Notes; v. 10, n. 1, p.399-406, 2017.

18.Burt RK, Craig R, Yun L, Halverson A, Quigley $\mathrm{K}$, Arnautovic I, et al. A pilot feasibility study of non-myeloablative allogeneic hematopoietic stem cell transplantation for refractory Crohn Disease [published online ahead of print, 2020 May 28]. Bone Marrow Transplant. 2020

TABLE 1 - SBTMO recommendations for AHSCT in autoimmune diseases

\begin{tabular}{c|c|c|c|c}
\multirow{2}{*}{\begin{tabular}{c}
\multirow{2}{*}{ Disease } \\
N
\end{tabular}} & $\begin{array}{c}\text { Autologous } \\
\text { transplantation }\end{array}$ & MSD & MUD & MMAD \\
\hline Multiple sclerosis & Recommended/I & Experimental/III & Not recommended/III & Not recommended/III \\
\hline Systemic sclerosis & Recommended/I & Experimental/III & Not recommended/III & Not recommended/III \\
\hline Crohn's disease & Recommended/II & Experimental/III & Not recommended/III & Not recommended/III \\
\hline
\end{tabular}

SBTMO: Brazilian Society of Bone and Marrow Transplantation; AHSCT: autologous hematopoietic stem cell transplantation. MSD: matched sibling donor; MUD: matched unrelated donor; MMAD: mismatched alternative donor. Table created by the authors. 